\title{
Luhmann, Lotman e o problema da fronteira: uma reflexão teórico- crítica em torno das categorias de inclusão e exclusão
}

\author{
Luhmann, Lotman and the problem of boundary: a critical reflexion of \\ the theoretical categories of inclusion and exclusion
}

http://dx.doi.org/10.5007/2178-4582.2016v50n2p354

Jan Steffens

Technische Universität Dresden, Dresden, Deutschland

Suene de Souza Dantas

Universidade Federal de Sergipe, Aracajú/SE, Brasil

\begin{abstract}
Este artigo tem por finalidade apresentar o atual debate sobre inclusão e exclusão na Alemanha. A reflexão teórico-crítica, aqui proposta, baseia-se numa discussão científica em torno da definição categórica de ambos os termos, e nos desafios provenientes desse embate. Para isso, com base nos teóricos Niklas Luhmann e Yuri Lotman, será problematizado o conceito de fronteira, concebida como uma dimensão espaço-temporal onde o diálogo entre sistemas psíquicos, e entre sistemas sociais, efetua-se. Neste sentido, poder-se-ia compreender a exclusão como um monólogo do "sistema de poder", o qual é produzido na dimensão espaço-temporal da fronteira. E a inclusão, como um diálogo firmado na fronteira do sistema. A sustentação desse diálogo se dá, tanto no reconhecimento dos direitos humanos e cidadãos, quanto numa "abertura para o outro", a qual implica a disposição para uma influência mútua e mudanças potenciais, através da experiência de um diálogo verdadeiro.
\end{abstract}

Palavras-chave: Inclusão; Exclusão; Fronteira; Teoria de Sistemas; Diálogo.
This paper intends to give insight to the recent debate in Germany about inclusion and exclusion and the existing difficulties in the scientific discussion with both categories, especially concerning a theoretical definition. The position of Luhmanns system theory will hereby be in the center of critical analysis. Furthermore, by introducing the theoretical concept of the boundary, which will be discussed not only as a closure of a system, but as a space of all social dialog between systems, it seeks another view on boundaries, similar to the category in the semiotic culture theory of Yuri Lotman. Exclusion in this perspective would be a monolog of reigning systems of power at the spatiotemporal space of a system boundary and a socially produced exclusion from partial systems, which are taking part in the transformation of the social system as a whole. Inclusion therefor would be a dia$\log$ at the boundaries between psychic and social systems, based on the appreciation of human and civil rights, which always includes the willingness to mutual influence and change through the other.

Keywords: Inclusion; Exclusion; Boundary; System theory; Dialog.

\section{Introdução}

$\mathrm{Na}$ Alemanha, a inclusão é um tema que, hoje, ocupa um grande espaço na agenda de discussão do Estado e da sociedade civil. Esse debate se originou com o movimento da educação integrativa, nos anos sessenta, a qual teve como seguimento, a educação inclusiva. Ambos os movimentos têm por finalidades incluir pessoas com deficiências e com necessidades especiais nas escolas, e implantar condições para o acesso a uma educação igualitária e 
aberta para todos. Adicionalmente, essa discussão engloba debates relacionados à questão de gênero, interculturalidade e migração.

De acordo com Hinz (2006, p. 98, tradução nossa ${ }^{1}$ ), na pedagogia, a inclusão é um conceito desenvolvido "com base nos direitos cidadãos, contra toda forma da marginalização social e que, por sua vez, busca assegurar o direito do desenvolvimento individual e participação social para todos, independente das suas necessidades pessoais de ajuda".

Com vista na consolidação de um sistema de educação inclusiva, a partir da Convenção de Direitos para Pessoas com Deficiências (UN - Behindertenrechtskovention, BRK), organizada pela Organização das Nações Unidas (ONU) em 2006, a inclusão tornou-se um tema político e pauta relevante na agenda educacional da Alemanha. Na referida convenção (reformulada em 2009), os países signatários acordaram que nenhuma pessoa com deficiência seria excluída do sistema educacional, assegurando assim, o direto à escola e educação para todos. "States Parties recognize the right of persons with disabilities to education. With a view to realizing this right without discrimination and on the basis of equal opportunity, States Parties shall ensure an inclusive education system at all levels and life long learning [...]" (UNITED NATIONS, 2006, p. 1).

Após a convenção, houve uma explosão de publicações sobre inclusão na pedagogia especial. Essa demanda, em torno da problemática: "como lidar com a heterogeneidade dentro das escolas e no decurso das aulas?", mobilizou, então, a criação de cursos específicos (de graduação e de mestrado) em universidades, voltados para a educação inclusiva e didática inclusiva. Por conseguinte, alguns estados firmaram em seus planos de governo, por intermédio de contratos entre os partidos da coligação, o comprometimento em efetivar o sistema da educação inclusiva, por parte das escolas.

Embora haja avanços e sinais positivos no tocante à construção de um sistema de educação mais inclusivo, os desafios a serem enfrentados são vultosos e dignos de problematização. Dentre estes, além da imprescindível reestruturação do espaço físico nas escolas, registra-se a necessidade de reorientação curricular e formativa para os estudantes, que serão futuros professores inseridos num novo sistema educacional, bem como o investimento, de ordem acadêmica e prática, em profissionais já formados e atuantes na área.

Contudo, o primeiro e maior desafio seria definir o que é inclusão e exclusão. A problemática se inicia ao adentrar-se nesse território discursivo, e

1 " $[\ldots]$ auf der Basis von Bürgerrechten argumentiert, sich gegen jede gesellschaftliche Marginalisierung wendet und somit allen Menschen das gleiche volle Recht auf individuelle Entwicklung und soziale Teilhabe ungeachtet ihrer persönlichen Unterstützungsbedürfnisse zugesichert sehen will.“ 
deparar-se com a falta de consenso, seja nas ciências da educação ou na política. Frente a essa "indefinição", ou melhor, à inexistência de concordância conceitual sobre inclusão/exclusão, a conjuntura se complexifica, tornando-se ambígua. Vê-se, então, a tentativa, por parte dos profissionais, de se estabelecer e construir um sistema mais inclusivo, embora não haja um conhecimento conceitual abrangente e concreto sobre a inclusão; algo que dificulta o real alcance de seu objetivo. Somado a isso, é observada uma focalização na escola, para a problematização da temática, ficando aquém do debate, outros setores da sociedade.

Outro ponto crucial a ser questionado é a "preferência" dada ao tema inclusão. Os discursos da educação e da pedagogia evidenciam a centralização do debate em torno da matéria inclusão, em detrimento da exclusão. Para alguns autores, das referidas áreas e das ciências sociais, este é um fenômeno que provoca certo estranhamento, considerando que a exclusão e a inclusão estão inter-relacionadas, pois são eventos dialéticos (DEDERICH, 2006). É possível visualizar tal "cisão" em grande parte das publicações sobre o tema, que ao falarem sobre inclusão, evitam problematizar a exclusão. Desse modo, a inclusão se torna uma palavra que serve para explicar tudo e nada ao mesmo tempo, adentrando no rol de termos descritos por Adorno (1964) como um "jargão".

Logo, como alegou Vygotskij (1987), à medida que uma palavra ou conceito é utilizado de modo indiscriminado e não cauteloso, para descrever diversificados fenômenos e processos, seu conteúdo se torna vazio. Ao se referir a esse tipo de conceitos, utilizados para explicarem todo e qualquer conteúdo, o autor faz uma comparação, afirmando que "entre o teto e o alicerce falta o edifício" (VYGOTSKIJ, 1985, p. 280, tradução nossa²).

Nos campos da educação e da pedagogia, a ausência de uma definição conceitual de inclusão, e consequentemente, também de exclusão, está relacionada com a falta de consenso sobre a temática na área da sociologia. Apesar de neste campo a discussão estar mais avançada e desenvolvida, há divergentes perspectivas, e estes contrastes dificultam conceituar e definir inclusão e exclusão. Como propôs Sina Farzin (2011), os problemas metodológicos advêm do desacordo, na teoria da sociologia, sobre o conceito de sociedade, pois, compreender o processo de inclusão ou exclusão depende da corrente teórica e do modo como as perguntas “o que é social?” e “o que é sociedade?” são respondidas.

Por fim, o viés do presente texto é descrever, em linhas gerais, como se configura o aparato discursivo sobre exclusão e inclusão na Alemanha. À vista disso, pretende-se elaborar uma análise crítica a partir do campo da sociologia, especialmente da teoria de sistemas. Buscar-se-á propor uma nova perspectiva 
de análise para aprimorar e avançar na discussão sobre inclusão/exclusão, tendo como foco reflexivo e analítico: o problema da fronteira.

A preocupação com os fenômenos de exclusão, os quais se atrelam à questão da desigualdade, é algo presente, já há algum tempo, na sociologia alemã, sobretudo nas obras dos autores: Kronauer (2002), Bude (2004), Stichweh (2005) e Schroer (2009). Apesar de algumas divergências, todos se aproximam do conceito de exclusão social e fazem referência ao sociólogo francês Robert Castel (2000).

A focalização em apenas um conceito da dialética inclusão/exclusão se faz novamente presente, porém, de forma inversa. Enquanto na educação, ou no debate político oriundo da convenção das Nações Unidas, enfatiza-se a inclusão; no campo sociológico, a tendência é explicitar os processos relacionados à temática exclusão.

Por isso, como afirma Sina Farzin (2011), é importante não pôr em foco as teorias que falam apenas de exclusão, como um fenômeno singular, mas sim, evidenciar aquelas que apresentam um fundamento teórico coerente, que visem desenvolver, de fato, um conceito de sociedade. Na Europa, pode-se citar Pierre Bourdieu (1992) com a teoria de campos sociais, Michel Foucault (1966) com a teoria de discursos e Niklas Luhmann $(1984,1997)$ com a teoria de sistemas; cada teoria com suas peculiaridades e diferenças, como alega Stichweh (2005). Segundo este autor, as citadas teorias podem ser consideradas referenciais para o desenvolvimento de uma sociologia da exclusão e da inclusão (STICHWEH, 2005).

Neste momento, com a finalidade de elucidar um debate sobre inclusão/ exclusão, apresentaremos a perspectiva luhmaniana desses conceitos, que tem como base a teoria de sistemas.

\section{O problema da exclusão na teoria de sistemas de Luhmann}

A conceptualização de exclusão e de inclusão, na teoria de sistemas, foi introduzida na Alemanha pelo sociólogo Niklas Luhmann (1981), que teve como referência em seus trabalhos, o sociólogo estadunidense Talcott Parsons. $\mathrm{O}$ conceito parsoniano de inclusão se refere à paulatina inclusão de atores excluídos, em subsistemas, no processo de desenvolvimento evolucionário da sociedade (LUHMANN, 1981). Luhmann (1981) também se apropriou do conceito de diferenciação funcional de Parsons, definida pela criação de sistemas parciais dentro de um sistema social, com funções específicas para todo o sistema. Na diferenciação funcional, todos os sistemas funcionais estão projetados para entrar em comunicação com os outros sistemas disponíveis. As- 
sim, com o aumento da comunicação ou das possibilidades de comunicação, na sociedade moderna, todos os subsistemas (ou sistemas parciais) estariam, supostamente, incluídos (SCHROER, 2009). Segundo Luhmann (1981), esse seria o processo de desenvolvimento da sociedade moderna.

De acordo com o teórico, a sociedade moderna é funcionalmente diferenciada com diversas partes separadas, como a economia, a política, o direito, a ciência, a religião, etc., tendo cada uma dessas partes, funções relevantes para a sociedade. Os humanos, atores sociais, não se integram completamente em apenas uma dessas partes, de forma separada ${ }^{3}$; e nem poderiam assim proceder, considerando a necessidade de agregar variados sistemas parciais ao mesmo tempo (FARZIN, 2011).

É importante frisar que, a princípio, os fenômenos - exclusão ou desigualdade - não eram o foco da teoria de sistemas de Luhmann (SCHOER, 2009). Entre os anos setenta e noventa, a abordagem operou, quase que exclusivamente, através do conceito de inclusão, mesmo com a existência da dicotomia inclusão/exclusão (FARZIN, 2011). Isso porque Luhmann, em acordo com Parsons, acreditou que a disseminação das condições da vida moderna, gradativamente resultaria numa "inclusão da população inteira nos encargos de cada subsistema funcional da sociedade" (LUHMANN, 1981, p. 25, tradução nossa ${ }^{4}$ ) e que, no processo de realização deste programa, desapareceriam todos os grupos "que não participam da vida social ou participam de forma marginalizada" (LUHMANN, 1981, p. 25, tradução nossa ${ }^{5}$ ).

A sociedade, na teoria de sistemas, é interpretada como operações de comunicação que implicam "a totalidade de considerações de todos os contatos possíveis" (LUHMANN, 1984, 33, tradução nossa'). Este conceito de sociedade significaria, então, a totalidade das comunicações, e na visão luhmaniana, o maior sistema de sociedade é o mundo; o mundo seria, então, a última instância de abrangência.

Logo, ao capturar a definição de sociedade do pensamento de Luhmann, baseada na lógica da diferenciação funcional, é possível identificar o porquê de a exclusão não ser alvo de reflexão em sua teoria. Embora o teórico não admitisse ou alegasse a inexistência de exclusão no mundo, para ele, no processo de diferenciação funcional das sociedades modernas, nós chegaríamos automaticamente a uma inclusão completa, tornando-se viável a comunicação de todos os sistemas funcionais.

\footnotetext{
3 Uma das críticas feitas a Luhmann está relacionada com o fato de ele pensar sistemas (como o sistema de saúde, o sistema educacional, por exemplo) sem a participação ativa dos humanos (FARZIN, 2011).

4 "[...] die Einbeziehung der Gesamtbevölkerung in die Leistungen der einzelnen gesellschaftlichen Funktionssysteme"

5 "[...] die am gesellschaftlichen Leben nicht oder nur marginal teilhaben"

6 " $6[. .$.$] als Gesamtheit der Berücksichtigung aller möglichen Kontakte."$
} 
Um fato conhecido que suscitou a reorientação teórica do autor e, provocou uma reelaboração da própria teoria, foi a realização, nos anos noventa, de uma viagem ao Brasil, onde o autor pôde conhecer as favelas de Rio de Janeiro (FARZIN, 2011; LUHMANN, 2005). Diante dessa realidade, foi possível visualizar de forma explícita (pela primeira vez), uma tentativa de integração da lógica do conceito de exclusão social, nas obras de Luhmann. Esse "incremento" tornou-se desafiante para a sua teoria de sistemas, pois o conceito de exclusão, em si, contradiz a lógica da diferenciação funcional, conceito-chave do arcabouço teórico do autor (FARZIN, 2011).

A dificuldade em conceituar a inclusão e a exclusão na teoria de sistemas é também visível no desenvolvimento da teoria, nas obras posteriores a Luhmann. Nassehi (2009), aluno de Luhmann, sinaliza que, nessa tradição luhmaniana, a inclusão "não é diferente do modo como os sistemas sociais consideram os humanos, como eles os integram num espaço de relevância, como desenvolvem ou limitam os seus espaços de ações" (NASSEHI, 2009, p.123, tradução nossa ${ }^{7}$ ). Para Nassehi (2009), os prisioneiros na prisão, os moradores das favelas, os exilados, e até os "candidatos da morte" estão inseridos nessa lógica de espaço de relevância, por isso, estariam incluídos ${ }^{8}$.

Essa definição de inclusão manifesta a dificuldade da teoria de sistemas em lidar ou elaborar um conceito de exclusão. Inclusive, este é o motivo pelo qual Nassehi (2009) aconselha, à sociologia, a abandonar o conceito. Assim sendo, é quase impossível não perceber que a teoria de sistemas, de algum modo, perdeu-se, principalmente com toda a formalidade e burocracias inerentes à própria metodologia. Além disso, tal perspectiva seria um exemplo dos modos de pensamento identificados por Dussel (2013) como essencialmente eurocentristas.

Uma fonte desses problemas conceituais está relacionada à utilização e interpretação de Luhmann de três conceitos da teoria da auto-organização: autopoiésis, fechamento operacional e acoplamento estrutural, elaborados nos anos sessenta pelos autores Humberto Maturana e Frascisco Varela. Esses conceitos serão apresentados doravante.

\section{A auto-organização como base da teoria de sistemas}

Maturana e Varela (1987), assim como Luhmann, foram profundamente influenciados pela obra "Leis da Forma" (Laws of Form), do matemático

\footnotetext{
$7 \quad$ "[...] nichts anderes bedeutet als die Art und Weise, wie soziale Systeme Menschen bezeichnen, sie in ihren Relevanzraum aufnehmen, ihren Handlungsraum zugleich entfalten und eingrenzen $[\ldots]^{\text {“ }}$

8 É possível perceber que as relações de poder não são consideradas nessa concepção de exclusão, aspecto esse enfatizado por outras teorias da sociologia (BOURDIEU, 1992).
} 
George Spencer-Brown (1994). Este autor intentou oferecer uma nova perspectiva para a percepção humana frente às complexas formas do mundo. No referido livro, o autor apresenta uma ideia que, apesar de no início parecer simples, influenciou inúmeros autores e disciplinas: todas as formas conhecidas e todas as estruturas do mundo começam com uma distinção. Nas palavras do autor:

[...] um universo começa a existir quando um espaço é separado ou dividido. A pele de um organismo vivo separa o exterior do interior. $\mathrm{O}$ mesmo faz a circunferência de um círculo num plano. Descobrindo o modo como representamos essa distinção, podemos começar a reconstruir, com uma precisão e uma cobertura aparentemente incomuns, as formas básicas existentes debaixo das superfícies das ciências linguísticas, matemáticas, físicas e biológicas, e podemos começar a ver como as leis familiares de nossa própria experiência se seguem inexoravelmente ao ato original de uma distinção (SPENCER- BROWN, 1997, p. XXXV, tradução nossa').

Para os biólogos chilenos Maturana e Varela (1987), os sistemas vivos são sistemas autopoiéticos. O conceito de autopoiesis refere-se à autocriação, à capacidade que um sistema tem de se produzir, organiza-se e se manter por si mesmo. A organização dos sistemas seria, então, o encadeamento de uma auto-organização de processos cíclicos e recursivos. Por recursão entende-se que cada estado do sistema produz o próximo estado do sistema.

Um atributo característico desse processo é a fronteira, pois os sistemas dependem dela para a separação entre unidade e ambiente, como acontece com a membrana nas células ou com a periferia sensória do corpo humano, por exemplo. Essa fronteira assegura a existência de uma dinâmica interna, do mesmo modo como assegura à dinâmica interna a possibilidade de criar essa fronteira. Os autores chamam esse processo de "enclausuramento operacional" (MATURANA; VARELA, 1987).

De modo geral, cada sistema autopoiético se encontra numa mudança estrutural permanente. Essa mudança é resultado da dinâmica interna, bem como é resultado da interação com o ambiente exterior. A interação com o ambiente, ou seja, com outros sistemas vivos, provoca perturbações (ou

\footnotetext{
9 " "...] das sein Universum zum Dasein gelangt, wenn ein Raum getrennt oder geteilt wird. Die Haut eines lebenden Organismus trennt eine Außenseite von einer Innenseite. Das gleiche tut der Umfang eines Kreises in einer Ebene. Indem wir in unserer Darstellungweise einer solchen Treenung nachspüren, können wir damit beginnen, die Formen, die der Sprachwissenschaft wie der mathematischen, physikalischen und biologischen Wissenschaft zugrunde liegen, mit einer Genauigkeit und in einem Umfang, die fast unheimlich wirken, zu rekonstruieren, und können anfangen zu erkennen, wie die vertrauten Gesetze unserer eigenen Erfahrung unweigerlich aus dem ursprünglichen Akt der Trennung erfolgen."
} 
irritações) na fronteira. Caso haja um caráter estável e recursivo, essas perturbações na fronteira serão interpretadas pelo sistema e integradas como informação nova na dinâmica interna. Esta nova informação muda a dinâmica interna, bem como as interações futuras com o ambiente. Dessa forma, as interações com o ambiente e a dinâmica interna se influenciam permanente e reciprocamente, formando uma história de mudança estrutural em cada sistema. Maturana e Varela (1987) chamam esse fenômeno de "acoplamento estrutural".

É, portanto, no cerne da interpretação de Luhmann sobre a ideia de fronteira, que se encontra o problema da exclusão. Como alega Farzin (2011), no desenvolvimento da teoria de sistemas, Luhmann fala, cada vez mais, sobre a fronteira e o enclausuramento operacional como um fechamento absoluto. O enclausuramento operacional se torna, então, mais rígido, e o ambiente irrevogavelmente separado do sistema. Já nas primeiras reflexões da teoria, o enclausuramento operacional ocupa um grande espaço nas reflexões teóricas, porém, somente nos anos noventa é que esse conceito passa a ser profundamente ligado à ideia de fronteira impermeável (FARZIN, 2011).

A princípio, Luhmann (1984) ainda falou sobre "fronteiras autogeradas", explicando-as a partir de metáforas como membrana, pele, muros, portas e postos fronteiriços. Essas metáforas designam a possibilidade de contato com o exterior, que é regulado através do próprio sistema. Porém, posteriormente, o autor passa a conceber o sistema como encerrado, fechado, ao ponto de não ser possível realizar um intercâmbio com o ambiente. Assim, a teoria de sistemas retira, cada vez mais, a capacidade do sistema de perceber ocorrências do ambiente externo. Segundo Farzin (2008, p. 200, tradução nossa ${ }^{10}$ ), "o exterior é retirado do sistema", e foi esse foco radical no fechamento do sistema, que ocasionou dificuldades e problemas para se explicar os próprios conceitos da teoria. Parece que o lado do ambiente, na distinção sistema/ambiente, está se tornando obsoleto.

A ênfase dada ao fechamento rígido do sistema gera questionamentos epistemológicos do tipo: como o ambiente influencia o sistema? Como o exterior irrita ou perturba o interior? Essas perguntas são fundamentais para o desenvolvimento dos conceitos de inclusão e exclusão, e por isso demandam reflexão e atenção. Fica, então, instalada uma dúvida sobre como funciona o acoplamento entre o sistema e o ambiente. Especificando, sobre como se dá o contato entre dois sistemas no ambiente, pois, sem nenhum contato não existe irritação, e sem a perturbação não há motivos ou motivações para uma mudança estrutural.

"Das Außen wird dem System entzogen." 


\section{A fronteira como um lugar de diálogo}

Para compreender os conceitos de exclusão e inclusão mediante perspectivas alternativas, é pertinente problematizar as discussões epistemológicas em torno das categorias: fechamento operacional e intercâmbio entre sistemas. Pode-se dizer que o entendimento de exclusão e inclusão está diretamente ligado à definição do contato social entre sistemas, e relacionado ao que se processa nas fronteiras dos sistemas. Na tentativa de explicar a estrutura do contato entre sistemas, a discussão será voltada para o espaço da fronteira. Com isso, pretende-se fornecer uma breve visão interdisciplinar, bem como outro entendimento e perspectiva sobre a temática.

O questionamento epistemológico seria: como é possível explicar o contato que influencia a dinâmica interna de um sistema? O acoplamento estrutural seria, neste caso, o demarcador desse contato entre o interior e o exterior. O contato do sistema com o ambiente é essencial para a dinâmica interna, tendo em vista que a história da própria mudança estrutural depende disso. Além do mais, torna-se difícil explicar a permanente mudança estrutural em sistemas vivos que se organizam por si mesmo, sem irritações (na linguagem luhmanniana), e sem nenhuma influência do ambiente.

Se as percepções sensoriais são apenas uma construção da dinâmica interna, do cérebro (MATURANA; VARELA, 1987), enfim, do humano, como se configuraria a estrutura desse contato entre sistemas? Para as teorias do construtivismo radical, a realidade é única e é, exclusivamente, uma construção subjetiva. Existe uma fenda insuperável entre a percepção e a realidade.

Wolfgang Jantzen $(1987,2012)$, em resumo de trabalhos das áreas de ciências naturais e ciências humanas, afirma que os autores pensam unicamente na percepção, quando falam sobre a constituição do sujeito, suprimindo as possibilidades de se reconhecer o mundo através do movimento próprio do sistema e ações. Isso significa que o construtivismo radical não considera, suficientemente, a quarta dimensão do tempo, ou seja, os processos temporais. O "movimento" abarca em si um aspecto temporal, sempre há movimento no espaço e no tempo, independe da percepção sensória. O tempo é irreversível. As mudanças das flutuações na fronteira têm caráter temporal, logo, são mudanças temporais. Esses processos temporais, referentes aos padrões de flutuação, existem independentemente das transformações sensórias. Flutuações temporais do ambiente podem ser percebidas dentro do sistema como consequências ou processos temporais com ritmos. Através dessas informações temporais existem possibilidades de uma construção do presente, do futuro e do passado, e através do ritmo é possível, até mesmo, antecipar estruturas futuras. Essas informações se tornam a base para 
as ações do sistema, e constroem novos movimentos, ritmos e reciprocidade (JANTZEN, 1987, 2012).

Por fim, por que essa travessia epistemológica seria propícia para pensar o problema da exclusão e da inclusão? Porque é nesse território discursivo que se pode encontrar um ponto crítico da teoria de Luhmann, e por sua vez, a reflexão-crítica proposta pelo artigo. Ao invés de supor a fronteira como um fechamento total, é preciso pensá-la como um espaço de interconexão entre os dois lados que ela separa, pois, as flutuações do ambiente, como perturbações (ou irritações), acontecem nesse espaço. Essas perturbações, quando provindas de outros sistemas vivos, têm um caráter recíproco, e é através dessa ligação recíproca entre sistemas, que ocorre o que Jantzen (2012) identifica como um diálogo entre sistemas na forma de acoplamento temporal. Ou seja, é possível haver um intercâmbio entre sistema e ambiente ou entre sistema e sistema. Segundo Jantzen e Feuser (2012), sistemas em sincronização temporal, em acoplamento de fases, já existem em nível primitivo dos sistemas vivos. Os autores se referem a estudos empíricos, tomando como exemplo a chamada ameba social (Dictyostelium discoideum), para explicar essas interações em reciprocidade no nível básico (JANTZEN, FEUSER, 2012; MATURANA; VARELA, 1987).

Qual significado teria essa referência para o problema da fronteira? $\mathrm{Na}$ tentativa de desenhar uma resposta, formular-se-á três hipóteses. A primeira é que a fronteira entre sistemas vivos não deve ser concebida como somente um espaço de fechamento ou de exclusão dos conteúdos de fora, pois é nesse espaço que também acontece toda forma de contato social entre organismos. A segunda é a existência do diálogo, concebido como estrutura temporal, e responsável pelo processo de mediação entre os sistemas. E a terceira é que a fronteira é organizada espaço-temporalmente, e essa concepção é crucial para o seu entendimento. Assim como todos os processos do mundo intersubjetivo, a organização de todos os sistemas vivos tem um caráter espaço-temporal. Eles estão em permanente mudança estrutural, movem-se no espaço e no tempo, e se influenciam reciprocamente (aparecem e somem). Nesse sentido, a fronteira se constitui espacialmente como relação, e na perspectiva temporal, constitui-se como processo (JANTZEN; BONET, 2014; JANTZEN; STEFFENS, 2014).

Adentrando no campo da psicologia, mas sem perder de vista a interdisciplinaridade, é possível perceber enormes semelhanças entre a concepção de diálogo na psicologia do desenvolvimento, sobretudo nas obras de Rene A. Spitz (1979), e as explicações epistemológicas dos mecanismos e funções da fronteira.

Em seus estudos sobre o fenômeno do hospitalismo, Spitz (1980) analisou as estruturas do diálogo entre mãe e filho. Ele descobriu que quando os filhos são isolados dos pais, ou de um diálogo com pessoas próximas, eles não só adoecem com mais facilidade, como também desenvolvem uma depressão 
anaclítica, ou até mesmo sintomas de marasmo, que podem ser letais (SPITZ, 1980). Em seu livro "Sobre o diálogo" (1979), o autor alega que o diálogo apresenta a reciprocidade como característica central, e reafirma a importância dessa reciprocidade para o desenvolvimento da criança (SPITZ, 1979).

Nos estudos mais recentes sobre as protoconversações e interações entre mãe e filho, o foco é direcionado para as harmonias de ritmos, para os diálogos através da sincronização de mímica, gestualidade e tom de vozes, etc. O ajustamento rítmico entre os parceiros, nesses primeiros contatos e interações, foi observado e analisado mediante técnicas modernas em diversos estudos, e os resultados obtidos por esses trabalhos são fascinantes. Em todos os casos, os processos temporais estão no centro das primeiras ligações entre humanos. O neurocientista Alan Schore (2001), por exemplo, fala sobre como se dão os processos de sincronização, em contextos de ressonância emocional, entre duas pessoas envolvidas num diálogo de apego.

Outra articulação é com as recentes teorias da neurociência sobre a análise de interações entre pais e filhos. Há um grande quantitativo de publicações sobre as estruturas temporais e recíprocas do diálogo, e tais publicações alegam que a parte mais importante do contato de apego é a sensibilidade para o ritmo do outro, bem como a adaptação de maneira harmônica (Attunement), entre os dois parceiros da interação (SCHORE, 2001; TREVARTHEN; AITKEN, 1994; TREVARTHEN, 2000, 2001).

Ao transferir as supracitadas hipóteses sobre intersubjetividade para o campo de teorias que tratam da cultura e da sociedade, é possível identificar semelhantes princípios entre sistemas sociais, a começar pelo processo de distinção através de uma fronteira. Caso seja tomado como referência o fechamento de um sistema social, ao modo de Luhmann, o problema da não percepção ou não explicação dos processos de exclusão persistirá. Não obstante, se o lugar da fronteira for pensado como um espaço de diálogo entre sistemas sociais, é possível superar os problemas associados à exclusão e à inclusão, na teoria de sistemas. A seguir, far-se-á referência a uma perspectiva teórica, sobre o problema da fronteira, considerada de grande relevância para a elucidação e entendimento das problemáticas centrais.

\section{Sistemas sociais e o problema da fronteira}

Um autor que pensou a sociedade a partir de processos espaço-temporais foi o semiótico e cientista cultural Yuri Lotman (2010a; 2010b). Em suas obras é possível encontrar um exemplo interessante sobre como discutir a fronteira e o diálogo entre culturas e grupos, que, na terminologia de Luhmann, corresponderia aos sistemas sociais. 
Em sua teoria semiótico-cultural, Lotman (2010a, 2010b) analisa os espaços diferentes de cultura humana, que podem ser nações, regiões, e até mesmo subculturas ou grupos pequenos, como famílias. Todos esses grupos ou espaços se organizam através da mediação de sinais e, com isso, eles produzem linguagem, símbolos próprios e únicos para o grupo. Este é o espaço da semiótica. Para compreender a organização semiótica, Lotman (2010a, 2010b) introduz o conceito de Semiosferas, que é similar ao conceito de Cronotopo de Bachtin (1986).

Semiosferas são espaços da cultura humana mediados através de sinais, os quais produzem novos sinais culturais pela própria cultura e, ao mesmo tempo, possibilitam a existência das culturas mediante a comunicação de linguagem. Cada humano, como sistema próprio, representa uma semiosfera, assim como participa da semiosfera da própria família e da própria cultura. Pode-se dizer que a semiosfera de toda humanidade está para o indivíduo, assim como a biosfera está para cada ser biológico.

Mesmo sendo espaços semióticos e culturais, as semiosferas requerem uma fronteira. Com a inexistência de uma fronteira, a semiosfera não seria semioticamente produtiva. A fronteira define a semiosfera e separa o conteúdo próprio do conteúdo estranho, ou seja, ela faz distinções entre o espaço interior e o exterior. Através disso, o sistema mantém sua própria identidade, ou individualidade, que é o espaço interior com uma estrutura semiótica própria. Por conseguinte, a fronteira é que produz a existência de um "Nós" e um "Eles" (LOTMAN, 2010a).

Tendo em vista que esse processo é válido para todas as formas de espaços culturais semioticamente ativos, quando um grupo ou uma cultura cria a própria organização, esse processo sempre acontece em relação a "outros" que não estão da mesma forma organizados (LOTMAN, 2010a). Esse mecanismo é tão presente que, mesmo não havendo muita diferença semiótica, a parte interior produz uma desorganização fictícia da parte exterior. Um dos exemplos que ele cita é a construção da diferença social na Europa, no século XIX. A então chamada civilização criou a desorganização de povos exteriores nomeados "bárbaros" e "selvagens", criando histórias imaginárias sobre eles. Esses construtos de uma desorganização de uma parte exterior sempre têm a função de uma organização interior.

Isto posto, é importante frisar que através da fronteira também se organiza o espaço interior da semiosfera ${ }^{11}$. A partir de uma distinção entre uma periferia semiótica e um centro semiótico na semiosfera, produz-se uma estru-

11 Cada semiosfera está dividida em várias sub-semiosferas, sendo que cada uma tem suas próprias fronteiras. Dentro de cada semiosfera há várias flutuações e movimentos de sub-semiosferas, assim como a sociedade, que tem vários movimentos de sistemas parciais (LOTMAN, 2010a, 2010b). 
tura hierárquica. Diante da existência de uma distinção, a periferia se situa como espaço mais próximo da fronteira, e o centro, o espaço mais distante dessa fronteira. É no centro, caracterizado pela rigidez e inflexibilidade, que as normas culturais são criadas e determinantes. No centro são organizadas as gramáticas da ação, e segundo Lotman (2010a), é nesse sistema semiótico que as normas sociais, regras de comportamento e a dita normalidade são produzidas. As estruturas do centro, caracterizadas por Lotman (2010a) como "sem cor" ou "pálidas", são tão discretas, tão "normais" ou adequadas, que, às vezes, se torna difícil ou impossível percebê-las (LOTMAN, 2010a, p.189).

Já na periferia, o funcionamento é outro, a lógica de ação é contrária ao que se passa no centro. O lugar da fronteira está bem distante das normas centrais e mais próxima da influência de outras semiosferas, sendo este, um espaço de processos semióticos acelerados. A periferia tem muita cor, não é discreta, difere do centro e apresenta uma gama de variações. É o lugar da novidade e também de resistência ao poder e às normas do centro. Mas, por que isso acontece? A resposta está muito relacionada ao modo como Lotman (2010a) descreve a estrutura da fronteira, similar a uma zona bilíngue. $O$ fato é que as semiosferas, ao estabelecerem um contato permanente com outros espaços semióticos, elas adquirem a função de um filtro de tradução bilíngue ou multilíngue. De acordo com Lotman (2010a, 182, tradução nossa ${ }^{12}$ ):

\begin{abstract}
O conceito da fronteira é ambivalente: Por um lado separa, e por outro, une. Uma fronteira sempre divide e pertence a ambos os lados das culturas vizinhas, a ambas semiosferas fronteiriças. A fronteira sempre é bilíngue ou polilíngue. Ela é um mecanismo para a tradução de textos de uma semiótica estranha a "nossa própria" semiótica, um lugar onde o "externo" é transformado em "interno". É uma membrana que filtra e transforma o texto alheio a ponto dele se tornar parte da semiótica interna da semiosfera, sem perder a característica estranha (LOTMAN, 2010a, p. 182, tradução nossa).
\end{abstract}

A fronteira é bilíngue, e por isso apresenta constantemente mudanças através de processos semióticos acelerados. Mediante o mecanismo bilíngue há a possibilidade de contato com a parte semiótica externa, criando-se assim uma semântica na forma de significados novos. Esse processo, que apresenta uma novidade para a semiosfera, não está sempre em acordo com

12 "Der Begriff der Grenze ist ambivalent: Einerseits trennt sie, andererseits verbindet sie. Eine Grenze grenzt immer an etwas und gehört folglich gleichzeitig zu beiden benachbarten Kulturen, zu beiden aneinandergrenzenden Semiosphären. Die Grenze ist immer zwei- oder mehrsprachig. Sie ist ein Übersetzungsmechanismus, der Texte aus einer fremden Semiotik in die Sprache „unserer eigenen“ Semiotik überträgt; sie ist der Ort, wo das „Äußere“ zum „Inneren“ wird, eine filternde Membran, die die fremden Texte stark transformiert., dass sie sich in die interne Semiotik der Semiosphäre einfügen, ohne doch ihre Fremdartigkeit zu verlieren.“ 
as normas do centro. Mas, se um conteúdo semiótico da fronteira consegue se impor, esse processo se move cada vez mais para o cerne da semiosesfera. Isso pode ocorrer no formato de normas de comportamento, de linguagem ou de moda.

Para exemplificar um desses processos de transição, Lotman (2010a) cita o fenômeno ocorrido com a calça "jeans". Na Europa, e também nos Estados Unidos, o "jeans" sempre foi um uniforme do trabalhador, e assim, parte de uma subcultura. No século 20 , a juventude, na intenção de subverter as semióticas da moda, e negar as normas de se vestir impostas pela cultura da época, ao se inclinar para o espaço da fronteira, descobriu o "jeans" e começou a usá-lo fora do contexto de trabalho. Esse posicionamento de estilo se disseminou em todos os espaços da cultura, a ponto que, hoje, é considerado normal vestir-se com "jeans", pois a vestimenta já faz parte da estrutura do centro. Por fim, considerando que, diferente do espaço fronteiriço, as estruturas semióticas do centro são, de modo geral, caracterizadas pela neutralidade, os processos que transitam da fronteira para o centro se alteram, tornando-se mais "pálidos" em seu percurso.

Com a disseminação de um processo intercorrente na fronteira, que aos poucos se direciona para o centro, é possibilitada, então, uma transformação do sistema. Lotman (2010a) mostra o exemplo da calça "jeans", e aqui também pode ser referida a história do Samba brasileiro. Estilo criado pelos escravos, logo, pela parte da população mais distante do centro do poder, o Samba surgiu na periferia do sistema e foi disseminado para toda cultura brasileira, mesmo diante das resistências do centro. Embora tenha ido de encontro às normas sociais do colonialismo, o Samba é hoje um processo difundido no e pelo centro, e é concebido como uma imagem que os brasileiros têm da própria cultura musical.

Logo, a fronteira é um permanente lugar de tradução entre o lado interno e o externo, é uma espécie de espaço de transição que se situa entre os dois lados. Segundo Lotman (2010a), essa função da fronteira, de separar o interior do exterior, é uma divisão elementar e ríspida, pois todo o espaço da semiosfera é formado por sub-semiosferas em níveis diferentes. É como uma nação compreendida por diversas subculturas com línguas próprias, sinais e identidades específicas. Essa analogia também se adequa para a constituição de uma família, pois cada membro atua como um subsistema que produz sinais diferentes, mesmo pertencendo a uma mesma organização semiótica, a uma mesma lógica das partes que formam o todo.

O diálogo, na concepção lotmaniana, representa o fundamento de cada bilinguismo e de todos os processos semióticos a ele atrelados. O diálogo, que demanda assimetria, ou seja, estruturas semióticas (como línguas) diferentes, 
acontece permanente e constantemente no espaço da fronteira, a qual exerce a função de um filtro de tradução. Ao passo que um diálogo sem a diferença semiótica não faz sentido, a diferença absoluta também não permite a existência de um diálogo. Um lado do diálogo precisa da imagem semiótica do outro para se construir, como numa simetria espelhada.

\section{Considerações finais: exclusão e inclusão}

Por fim, como essas discussões se aproximam dos conceitos de exclusão e inclusão? Como explicitado, em Luhmann a inclusão é entendida como uma simples consideração do outro através da percepção, e não da ação. Esta via resulta numa invisibilidade da exclusão, marcada justamente pelo que Boaventura de Souza Santos descreve como a razão indolente do norte (JANTZEN; BONET, 2014).

Diante disso, questiona-se: precisamos de uma definição teórica unificadora de exclusão e de inclusão? Ou seria mais adequado pensar em múltiplas definições de exclusão e de inclusão, oriundas das múltiplas perspectivas existentes? E quem poderia definir exclusão, se não os excluídos? E quem são esses excluídos? Faz sentido seguir com o vocabulário inclusão e exclusão, ou seria melhor abandonar a discussão sobre esses conceitos tão difíceis de definir e pensar em novas categorias de análise? Todos esses questionamentos, de ordem teorética, são feitos em contextos de estudos empíricos sobre os fenômenos de exclusão e desigualdade.

Se tomarmos como base estudos que mostram como esses processos excludentes e desiguais têm um efeito psicossocial negativo sobre as pessoas que deles são alvo, reconheceríamos sua relevância. Como exemplo, pode-se citar o grande estudo, na área das ciências sociais, dos autores Kate Pickett e Richard Wilkinson (2009) sobre a relação entre a desigualdade numa sociedade e os vários problemas sociais. Na conclusão de um trabalho de 20 anos de pesquisa, que visou comparar dados de vários governos sobre problemas sociais como desintegração social, sofrimento psíquico (psicoses, depressão, etc.) problemas de saúde, baixa expectativa de vida, aumento do consumo de drogas, crescimento do índice de violência, pouca mobilidade social, prisões cheias, educação de pouca qualidade, entre outras; os autores perceberam que esses aspectos estão relacionados com o grau de desigualdade numa sociedade, ou seja, com as relações de inclusão e exclusão ${ }^{13}$ (WILKINSON; PICKETT, 2009). Ao mesmo tempo, estudos da neurologia apontam que a exclusão de um grupo provoca uma ativação nas mesmas regiões cerebrais

13 É importante estar ciente de que os problemas citados acontecem tanto em situações de pobreza e exclusão, quanto no lado dos ricos (WILKINSON; PICKETT, 2009). 
que são ativadas durante uma dor física (EISENBERG; LIEBERMANN; WILLIAMS, 2003). Portanto, é evidente o significado e importância de uma elaboração conceitual coerente para identificar tais fenômenos.

Marcar a exclusão apenas como "a separação de pessoas na sociedade" é simplista e problemático. Nessa visão topológico-social, os incluídos seriam aqueles que estão dentro, e os excluídos aqueles que estão fora. A exclusão pode até se apresentar através da segregação, entretanto, elas não são a mesma coisa. A perspectiva de que exclusão e inclusão ocupam espaços resumidos em relação a algo que está dentro ou fora, desorienta, pois, pessoas podem ser excluídas em qualquer lugar, mesmo vivendo no centro de uma cidade, por exemplo. É importante observar que a relação exclusão/inclusão não se trata de lugares fixos, e sim de processos espaço-temporais, e que a análise dos fenômenos não pode ser procedida separadamente. Pensar exclusão implica, além de uma análise dos espaços excluídos, esquecidos, dominados, uma análise do espaço hegemônico e dos centros de poder. Como explica Lotman (2010a), o centro é onde se constrói o mecanismo da exclusão, e é nele onde o processo de exclusão tem sua origem. Portanto é crucial a análise dessa lógica interna da operação de um sistema, que constrói um continuum de posições entre exclusão e inclusão. No sistema educacional alemão, por exemplo, baseado num processo de separação e seleção através da avaliação de inteligência com notas, é desafiante, e até mesmo contraditório, falar-se em inclusão, enquanto essa lógica, em si excludente, não for radicalmente transformada.

Por fim, tendo em vista que todas as semiosferas, ou sistemas, entram em contato através da fronteira, é manifesta a pertinência de sua análise. São essas fronteiras que decidem qual conteúdo pode ou não entrar, passar e atravessar.

A fronteira de um sistema autopoiético, a exemplo de uma célula ou um organismo metacelular, como o corpo humano (MATURANA; VARELA, 1987), representa o lugar do contato social, do mesmo modo como a fronteira de um sistema social e semiótico (de uma cultura ou família). Só através desse contato social na fronteira é possível manter a dinâmica interna e a mudança estrutural permanente do sistema. A fronteira da semiosfera representa o lugar da nova produção semiótica. O centro, que é rígido e estagnante, assegura certa estabilidade necessária ao sistema, mas os processos subculturais da periferia representam mudanças e novidades para o centro, ou seja, a troca social que para todo e qualquer sistema evoluir. Inclusive, são esses processos da fronteira que possibilitam a existência de estruturas de resistência contra o poder do centro.

Segundo Lotman (2010a), o centro da semiosfera é o lugar onde a cultura ou a sociedade definem suas normas sociais. Quem não obedece e se adéqua às normas estabelecidas, será cada vez mais compelido à periferia. Aqui a re- 
lação entre centro e periferia, na concepção da semiosfera de Lotman (2010a), é similar à concepção do campo de poder, de Bourdieu (1992).

Quanto mais uma pessoa se encontra próxima à periferia da semiosfera, maior será sua diferença semiótica em relação ao centro; e quanto maior for a sua diferença semiótica com o centro, mais difícil será participar da construção dessas semiosferas, ou seja, expande-se assim a possibilidade de conflitos semióticos entre periferia e centro.

Esses conflitos não apenas existem entre periferia e centro, mas também, na parte interior, a qual se divide em subpartes, subculturas etc. Esses sistemas parciais, como Luhmann o chama, também são sistemas espaço-temporais e formam fronteiras dentro de uma semiosfera. No caso da cultura de uma nação isso significa que existem várias subculturas que produzem aquela cultura.

Contudo, caso os processos subculturais sejam "empurrados" para a periferia, menor será a probabilidade de eles participarem na construção permanente das normas culturais da nação, ou seja, essas partes periféricas pouco participam na transformação permanente do sistema. Como, então, entender esse processo? Sistemas (autopoiéticos ou sociais) se dividem em diferentes subsistemas. O corpo humano é separado por vários processos internos, e cada um apresenta um sistema funcional. Do mesmo jeito uma semiosfera é separada em vários sistemas semióticos dentro dela, como a família em membros, a cultura em participantes, a nação em cidadãos. Cada um apresenta um subsistema em diálogo com os outros subsistemas, e esse diálogo acontece na fronteira de cada sistema. Se o diálogo acontece entre sistemas, processos como a cooperação, a aprendizagem e o desenvolvimento serão possibilitados, em ambos os lados. Isso inclui uma participação dos sistemas, através do diálogo, na permanente construção de um sistema social mais amplo. Se não houver um diálogo entre os subsistemas, cada vez mais, essa negação de diálogo, de contato social e de participação na construção do todo, constituirá o processo de exclusão.

Nesse sentido, a exclusão seria, portanto, aquele processo que "empurra" as pessoas, grupos, subculturas, enfim, subsistemas, para a periferia, tendo essas poucas oportunidades de participação nas estruturas de poder do centro, ou como disse Vidal-Fernandez (2009), que elimina os excluídos do processo narrativo da própria cultura ou sociedade. Por fim, enquanto a exclusão poderia ser configurada como um contínuo de não-participação construído pela sociedade, a inclusão seria exatamente esse diálogo na fronteira, que, cada vez mais, possibilita a mudança de estruturas, no sentido de emancipação dessas pessoas que estão forçadas ao polo do não-poder.

Um bom exemplo para a ausência de diálogo na fronteira, sobre a invisibilidade da exclusão como um processo, foi descrito por Fernando Braga da 
Costa (2004) em seu livro - Homens invisíveis: relatos de uma humilhação social. O autor passou anos trabalhando como gari na sua própria universidade em São Paulo, junto a outros trabalhadores, com uniforme laranja, e alegou nunca ter sido percebido ou reconhecido por amigos, estudantes ou professores (COSTA, 2004).

A invisibilidade, como forma de exclusão, é então construída através de um processo social, e na relação com o outro, uma pessoa não é vista como humano, como sujeito de relevância, como digna de direitos humanos e cidadãos. Isso ocorre pelo fato de que, a pessoa que é alvo da invisibilidade, não é percebida como parceira potencial para um diálogo verdadeiro na fronteira do próprio sistema (social, cultural etc.).

Nesse sentido, a exclusão seria um monólogo das estruturas de poder na fronteira. A falta de diálogo, que está na base da exclusão, tem como resultado a redução e objetificação do sujeito. É um processo de despersonalização, coisificação ou criação de invisibilidade que acontecem todos os dias, através da língua e do comportamento, através da semiótica da semiosfera. Poder-se -ia, então, afirmar que todos esses mecanismos são resultado de uma falta de diálogo na fronteira.

Os processos de inclusão estariam presentes nesse diálogo da fronteira, um diálogo constituído pela reciprocidade e ressonância. Isso conta para o diálogo entre indivíduos, bem como entre grupos sociais e sistemas culturais. É importante enfatizar que esse diálogo implica, sempre, uma abertura para a alteridade, semelhante à concepção de diálogo verdadeiro de Paulo Freire e da conscientização (FREIRE, 1974). Cada vez que alguém entra num diálogo com o outro, observa-se uma pequena mudança (estrutural) de cada um dos participantes. Pensando pelo viés espaço-temporal, após a existência de um diálogo entre duas pessoas, cada interlocutor muda, adquire mais experiências e uma nova perspectiva vinculada à outra subjetividade. O diálogo não é reversível. Não há duas pessoas entrando num mesmo diálogo duas vezes, do mesmo modo que não se pode ler um mesmo livro duas vezes, pois as experiências vividas no primeiro encontro construíram outra base de leitura para o segundo encontro. É como disse Heráclito: não se pode percorrer duas vezes o mesmo rio (STÖRIG, 1996).

\section{Referências}

ADORNO, T. W. Der Jargon der Eigentlichkeit. Suhrkamp: Frankfurt/M, 1964.

BACHTIN, M. M. Untersuchungen zur Poetik und zur Theorie des Romans. Berlin: Aufbau-Verlag, 1986. 
STEFFENS, Jan, DANTAS, Suene de Souza. Luhmann, Lotman e o problema da fronteira: uma...

BOURDIEU, P. Die verborgenen Mechanismen der Macht. Hamburg: VSA Verlag (Schriften zu Politik \& Kultur 1), 1992.

BUDE, H. Das Phänomen der Exklusion. Mittelweg 36, v. 13, n. 4, 2004.

CASTEL, R. Die Fallstricke des Exklusionsbegriffs. Mittelweg 36, v. 9, n. 3, p. 11-25, 2000.

COSTA, F. B. Homens invisíveis: relatos de uma humilhação social. São Paulo: Globo, 2004.

DEDERICH, M. Exklusion. In: DEDERICH, M. et al. (Hrsg.). Inklusion statt Integration? Gießen, 2006, p. 11-27.

DUSSEL, E. Der Gegendiskurs der Moderne. Kölner Vorlesungen. Wien, 2013.

EISENBERGER, N., LIEBERMAN, M., WILLIAMs, K. Does Rejection Hurt? An fMRI Study of Social Exclusion. Science, v. 302, n. 5643, p. 290-292, 10 October 2003.

FARZIN, S. Sichtbarkeit durch Unsichtbarkeit: Die Rhetorik der Exklusion in der Systemtheorie Niklas Luhmanns. Soziale Systeme, v. 14, n. 2, p. 191-209, 2008.

FARZIN, S. Die Rhetorik der Exklusion. Velbrück Wissenschaft. Weilerswist, 2011.

FOUCAUlT, M. Das Denken des Außen. S. 670-697 in: Ders. (2001), Dits et Ecrits, Bd. I. Frankfurt a.M.: Suhrkamp, 1966.

FREIRE, P. Erziehung als Praxis der Freiheit. Stuttgart, 1974.

HINZ, A. Inklusion. In: ANTOR, G.; BLEIDICK, U. (Hrsg.). Handlexikon der Behindertenpädagogik. Stuttgart, 2006. p. 97-99.

JANTZEN, W. Allgemeine Behindertenpädagogik Bd. 1. Sozialwissenschaftliche und psychologische Grundlagen. Weinheim: Beltz, 1987.

Am Anfang war der Sinn. Marburg: BdWi. Berlin: Lehmanns, 2012.

; BONET, A. J. A. Inklusive Erziehung und Epistemologie des Südens: Beiträge zur Behindertenpädagogik. Behindertenpädagogik, v. 53, n. 1, p. 4-29, 2014.

; FEUSER, G.; Die Entstehung des Sinns in der Weltgeschichte. In: JANTZEN, W. Am Anfang war der Sinn. Marburg: BdWi. Berlin: Lehmanns, 2012. p. 79-113.

; STEFFENS, J. Inklusion und das Problem der Grenze. Behinderte Menschen. Zeitschrift für gemeinsames Leben, Lernen und Arbeiten, n. 4/5, p. 48-53, 2014.

KRONAUER, M. Exklusion. Die Gefährdung des Sozialen im hoch entwickelten Kapitalismus. Frankfurt/New York, 2002.

LOTMAN, J. M. Die Innenwelt des Denkens. Suhrkamp: Frankfurt/M, 2010a.

Kultur und Explosion. Suhrkamp: Frankfurt/M, 2010b. 
LUHMANN, N. Politik im Wohlfahrtsstaat. München, 1981.

1984.

Soziale Systeme. Grundriß einer allgemeinen Theorie. Suhrkamp Frankfurt a. M,

. Die Gesellschaft der Gesellschaft. Suhrkamp Frankfurt a. M, 1997.

2005 .

Einführung in die Theorie der Gesellschaft. Heidelberg: Carl-Auer-Systeme Verlag,

MATURANA, H., VARELA, F. Der Baum der Erkenntnis. München: Piper, 1987.

NASSEHI, A. „Exklusion“ a als soziologischer oder sozialpolitischer Begriff? In: Exlusion. Die Debatte über die "Überflüssigen”. Hrsg: Bude, H.; Willisch, A. Suhrkamp Verlag Frankfurt a. M, 2009. p. 121-130.

SCHORE, A. N. The Effects of Secure Attachment Relationship on Right Brain Development, Affect Regulation, and Mental Health. Infant Mental Health Journal, v. 22, p. 7-66, 2001.

SCHROER, M. Die im Dunkeln sieht man doch. Inklusion, Exklusion und die Entdeckung der Überflüssigen. In: Exlusion. Die Debatte über die "Überflüssigen”. Hrsg: Bude, H.; Willisch, A. Suhrkamp Verlag Frankfurt a. M, 2009.

SPENCER-BROWN, G. Laws of Form. Gesetze der Form. Lübeck: Bohmeier, , 1997.

SPITZ, R. A. Vom Dialog. Stuttgart, 1979.

. Vom Säugling zum Kleinkind“, Stuttgart: Ernst Klett Verlage, 1980.

STICHWEH, R. Inklusion und Exklusion. Bielefeld, 2005.

STÖRIG, H. J. Kleine Weltgeschichte der Philosophie. Fischer, Frankfurt a. M, 1996.

TREVARTHEN, C. Musicality and the Intrinsic Motive Pulse: Evidence from Human Psychobiology and Infant Communication. Musicae Scientiae. Special Issue, 1999-2000, p. 155215 .

. Intrinsic Motives for Companionship in Understanding. Infant Mental Health Jour-

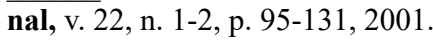

; AITKEN, K. J. Brain Development, Infant Communication, and Empathy Disorders. Development and Psychopathology, v. 6, p. 597-633, 1994.

UNITED NATIONS. Committee on the Rights of Persons with Disabilities. Convention on the Rights of Persons with Disabilities. 2006. Disponível em: $<$ http://www.ohchr.org/EN/ HRBodies/CRPD/Pages/ConventionRightsPersonsWithDisabilities.aspx >. Acesso em: abr. 2015.

VIDAL-FERNÁNDEZ, F. Pan y rosas: fundamentos de exclusión social y empoderamiento. Caritas: Madrid, 2009 
VYGOTSKIJ, L.S. Ausgewählte Schriften. Bd. 2. Köln, 1987.

WILKENSON, R.; PICKETT, K. The Spirit Level. Why More Equal Societies Almost Always Do Better. Allen Lane, Penguin Books, London, 2009.

Submissão: $27 / 09 / 2015$

Revisão: 03/06/2016

Aceite: 16/07/2016

Jan Steffens é colaborador de ensino e pesquisa no Departamento de Educação, Cadeira de Educação Inclusiva, Universidade Técnica de Dresden, Alemanha Doutora em Educação pela Universidade de Bremen, Alemanha E-mail: jan.steffens@tu-dresden.de

Suene de Souza Dantas é mestre em Sociologia pela Universidade Federal de Sergipe (UFS). Graduada em Psicologia pela Universidade Federal do Vale do São Francisco (UNIVASF). Psicóloga do aconselhamento a vítimas de violência provocada por motivações racistas e direitistas, Dresden, Alemanha. (Opferberatung für Betroffene rechtsmotivierter und rassistischer Gewalt, Dresden, Deutschland). E-mail: suene.dantas@,hotmail.com 